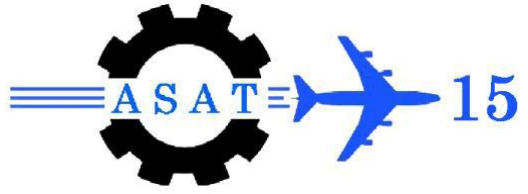

\title{
Dynamic Performance of a Three-Wheeled Vehicle Steering System, Part 2: Steer by Wire and Vehicle Dynamics during Steering
}

\author{
M.T. Heshmat ${ }^{*}$, M. Abdel-Aziz ${ }^{\dagger}$, M. Galal Rabie ${ }^{\ddagger}$, M. Sabry Dwidar ${ }^{\S}$
}

\begin{abstract}
This paper is complementary to Part 1, [1], submitted in the present conference and deals with the dynamic behavior of an aircraft (three-wheeled heavy vehicle) during taxing. An electro-hydraulic servo valve EHSV with a PI controller is modeled and incorporated into the hydraulic power steering system as an equivalent replacement to the directional control valve assembly presented in Part 1. The design parameters values of EHSV are tuned to give similar response to that of DCV assembly. Moreover, the steering hydraulic system is integrated into a complete vehicle handling model using MATLAB-SIMULINK to assess the dynamic behavior of the vehicle under various designs and operating conditions. The transient and steady state responses of the vehicle are examined.
\end{abstract}

Keywords: Steering, 3-wheeled vehicle, hydraulic, electro-hydraulic servo, directional, control, valve, modeling, simulation, dynamic, handling.

\section{Nomenclature}

$\mathrm{A}_{\mathrm{a}} \quad$ Spool valve restrictions area (a), $\mathrm{m}^{2}$.

$A_{b} \quad$ Spool valve restrictions area (b), $\mathrm{m}^{2}$.

$A_{c} \quad$ Spool valve restrictions area (c), $\mathrm{m}^{2}$.

$A_{d} \quad$ Spool valve restrictions area $(d), m^{2}$.

$\mathrm{A}_{\mathrm{P}} \quad$ Piston side area, $\mathrm{m}^{2}$.

$a_{n} \quad$ Normal component of the absolute acceleration of the vehicle, $\mathrm{m} / \mathrm{s}^{2}$.

$\mathrm{a}_{\mathrm{t}} \quad$ Tangential component of the absolute acceleration of the vehicle, $\mathrm{m} / \mathrm{s}^{2}$.

$\mathrm{a}_{\mathrm{xcg}} \quad$ The component along the longitudinal axis of the absolute acceleration of the center of gravity of the vehicle, $\mathrm{m} / \mathrm{s}^{2}$. The component along the lateral axis of the absolute acceleration of the center of gravity of the vehicle, $\mathrm{m} / \mathrm{s}^{2}$.

B Bulk modulus of oil, Pa.

b Rear wheels track, m.

$\mathrm{C}_{\mathrm{d}} \quad$ Discharge coefficient.
$\mathrm{C}_{\alpha \mathrm{f}} \quad$ Cornering stiffness of front tire, N/rad.

$\mathrm{C}_{\alpha \mathrm{r}}$ Cornering stiffness of each rear tire, N/rad.

c Spool radial clearance, $m$.

$\mathrm{e}(\mathrm{t})$ Error signal, A.

$\mathrm{F}_{\mathrm{rf}} \quad$ Rolling resistance force of the front tire, $\mathrm{N}$.

$\mathrm{F}_{\mathrm{rr}} \quad$ Total rolling resistance force of the rear tires, $\mathrm{N}$.

$\mathrm{F}_{\mathrm{SF}} \quad$ Side force, $\mathrm{N}$.

$\mathrm{F}_{\mathrm{sp}} \quad$ Force acting at the extremity of the feedback spring, $\mathrm{N}$.

$\mathrm{F}_{\mathrm{yf}} \quad$ Cornering force of front tire, $\mathrm{N}$.

$\mathrm{F}_{\mathrm{yr}}$ Total cornering force of the rear tires, N.

$\mathrm{f}_{\mathrm{rr}} \quad$ Coefficient of rolling resistance.

$\mathrm{f}(\mathrm{t}) \quad$ Feedback signal, A.

\footnotetext{
* Egyptian Armed Forces, Egypt.

$\dagger$ Dr Eng. Faculty of Engineering, Ain Shams University, Cairo, Egypt.

* Professor of Mech. Engineering, Modern Academy for Engineering and Technology, Cairo, Egypt.

$\S$ Professor. Faculty of Engineering, Ain Shams University, Cairo, Egypt.
} 
G(s) The transfer function.

g Acceleration due to gravity, $\mathrm{m} / \mathrm{s}^{2}$.

$\mathrm{h}_{\mathrm{cg}} \quad$ c.g height, $\mathrm{m}$.

$\mathrm{I}_{\mathrm{e}}(\mathrm{s})$ The Laplace transform of the system input.

$\mathrm{I}_{\mathrm{z}} \quad$ Vehicle yaw mass moment of inertia, $\mathrm{kg} . \mathrm{m}^{2}$.

$\mathrm{i}_{\mathrm{b}} \quad$ Feedback current, $\mathrm{A}$.

$i_{c} \quad$ Control current, $A$.

$\mathrm{i}_{\mathrm{e}} \quad$ Torque motor input current, $\mathrm{A}$.

J Vertical distance between c.g and the rollover axis $\mathrm{OF}$ in the $\mathrm{x}_{\mathrm{cg}}-\mathrm{y}_{\mathrm{cg}}$ plane, $\mathrm{m}$.

$\mathrm{K}_{\mathrm{FB}} \quad$ Feedback gain, $\mathrm{A} / \mathrm{m}$.

$\mathrm{K}_{\mathrm{us}} \quad$ Under steer coefficient, rad.

$\mathrm{K} \quad$ Proportional gain.

$\mathrm{L}_{\mathrm{f}} \quad$ Flapper length, $\mathrm{m}$.

$\mathrm{L}_{\mathrm{sp}} \quad$ Feedback spring and flapper length, $\mathrm{m}$.

L Wheel base, $\mathrm{m}$.

$l_{1} \quad$ Distance between front axle and center of gravity of the vehicle, $m$.

$l_{2} \quad$ Distance between rear axle and center of gravity of the vehicle, $\mathrm{m}$.

$\mathrm{m} \quad$ Vehicle mass, $\mathrm{kg}$.

$\mathrm{P}_{1} \quad$ Pressure in the left side of the flapper valve, $\mathrm{Pa}$.

$\mathrm{P}_{2} \quad$ Pressure in the right side of the flapper valve, $\mathrm{Pa}$.

$\mathrm{P}_{3} \quad$ Pressure in the flapper valve return chamber, $\mathrm{Pa}$.

$\mathrm{P}_{\mathrm{P}} \quad$ Pressure at the supply line $(\mathrm{P}), \mathrm{Pa}$.

$\mathrm{P}_{\mathrm{T}} \quad$ Pressure at the return line (T), $\mathrm{Pa}$.

$\mathrm{Q}_{1} \quad$ Flow rate in the left orifice, $\mathrm{m}^{3} / \mathrm{s}$.

$\mathrm{Q}_{2} \quad$ Flow rate in the right orifice, $\mathrm{m}^{3} / \mathrm{s}$.

$\mathrm{Q}_{3} \quad$ Left flapper nozzle flow rate, $\mathrm{m}^{3} / \mathrm{s}$.

$\mathrm{Q}_{4} \quad$ Right flapper nozzle flow rate, $\mathrm{m}^{3} / \mathrm{s}$.

$\mathrm{Q}_{5} \quad$ Flapper valve drain flow rate, $\mathrm{m}^{3} / \mathrm{s}$.

$\mathrm{Q}_{\mathrm{a}} \quad$ Flow rates through the spool valve restriction (a), $\mathrm{m}^{3} / \mathrm{s}$.

$\mathrm{Q}_{\mathrm{b}} \quad$ Flow rates through the spool valve restriction $(b), \mathrm{m}^{3} / \mathrm{s}$.

$\mathrm{Q}_{\mathrm{c}} \quad$ Flow rates through the spool valve restriction (c), $\mathrm{m}^{3} / \mathrm{s}$.

$Q_{d} \quad$ Flow rates through the spool valve restriction $(\mathrm{d}), \mathrm{m}^{3} / \mathrm{s}$.

$\mathrm{R}_{1} \quad$ Distance between midpoint of the rear wheels track and the turning center $\mathrm{C}$, m.

$\mathrm{R}_{\mathrm{cg}} \quad$ Turn radius of the vehicle c.g, $\mathrm{m}$.

$R_{f} \quad$ Reaction force on the front wheel assembly, N.
$\mathrm{T}_{\text {th }} \quad$ Vehicle engine thrust, $\mathrm{N}$.

$\mathrm{T}_{\mathrm{tm}}$ Torque of electromagnetic torque motor, N.m.

$\mathrm{u}(\mathrm{t})$ Control signal, A.

$\mathrm{V}_{3} \quad$ Volume of the flapper valve return chamber, $\mathrm{m}^{3}$.

$\mathrm{V}_{\mathrm{Ao}} \quad$ Initial volume of the cylinder chamber (A), piping and tubing, $\mathrm{m}^{3}$.

$\mathrm{V}_{\mathrm{Bo}} \quad$ Initial volume of the cylinder chamber (B), piping and tubing, $\mathrm{m}^{3}$.

$\mathrm{v}_{\text {char }}$ Characteristic speed, $\mathrm{m} / \mathrm{s}$.

$\mathrm{v}_{\text {roll }}$ Vehicle rollover speed, $\mathrm{m} / \mathrm{s}$.

$v_{\mathrm{xcg}}$ The component of the velocity $\mathrm{v}_{\mathrm{cg}}$ of the center of gravity along the axes$\mathrm{o}_{\mathrm{cg}} \mathrm{X}_{\mathrm{cg}}, \mathrm{m} / \mathrm{s}$.

$v_{y c g}$ The component of the velocity $v_{c g}$ of the center of gravity along the axes$\mathrm{o}_{\mathrm{cg}} \mathrm{y}_{\mathrm{cg}}, \mathrm{m} / \mathrm{s}$.

$\mathrm{W}_{\mathrm{f}} \quad$ Normal load on the front wheel assembly, $\mathrm{N}$.

$\mathrm{W}_{\mathrm{r}} \quad$ Normal load on each rear wheel assembly, $\mathrm{N}$.

W Vehicle weight, N.

$\mathrm{X}(\mathrm{s})$ The Laplace transform of the system output.

$\mathrm{X}_{\mathrm{F}} \quad$ Flapper displacement on the level of jet nozzles, $\mathrm{m}$.

$\mathrm{x} \quad$ Spool displacement, $\mathrm{m}$.

$\mathrm{x}(\mathrm{t})$ Input signal, A.

$\mathrm{y}$ Steering actuator piston displacement, $\mathrm{m}$.

z Pedal displacement, $m$.

$\vartheta \quad$ Armature rotation angle, rad.

$\mu_{\mathrm{ms}} \quad$ Measured tire/road adhesion coefficient.

$\mu \quad$ Threshold vehicle/road adhesion coefficient.

$\Omega_{\mathrm{z}} \quad$ Angular speed about the $\mathrm{z}_{\mathrm{cg}}$ axis, $\mathrm{rad} / \mathrm{s}$.

$\varepsilon \quad$ Angle between the centrifugal force and the centrifugal force component $\mathrm{F}_{\mathrm{c}} \cos \varepsilon$, rad.

$\lambda$ Angle between the centrifugal force and the vehicle longitudinal axis, rad. Oil density, $\mathrm{kg} / \mathrm{m}^{3}$.

$\varphi \quad$ Angle between rear wheels track and the rollover axis $\mathrm{OF}$ in the $\mathrm{x}_{\mathrm{cg}}-\mathrm{y}_{\mathrm{cg}}$ plane, rad.

$\omega \quad$ Width of ports on the valve sleeve, m. 


$\begin{array}{llll}\mathrm{R}_{\mathrm{i}} & \text { Resistance to internal leakage, N.s } / \mathrm{m}^{5} . & \mathrm{t} & \text { Ultimate period, } \mathrm{s} . \\ \mathrm{R}_{\mathrm{r}} & \text { Reaction force on each rear wheel } & \mathrm{t}_{\mathrm{o}} & \text { Delay time, } \mathrm{s} . \\ & \text { assembly, } \mathrm{N} . & \delta & \text { Steering angle, rad. } \\ \mathrm{T}_{\mathrm{d}} & \text { Derivative time, } \mathrm{s} . & \alpha_{\mathrm{f}} & \text { Slip angle of the front tire, rad. } \\ \mathrm{T}_{\mathrm{i}} & \text { Integral time, } \mathrm{s} . & \alpha_{\mathrm{r}} & \text { Slip angle of each rear tire, rad. }\end{array}$

$\begin{array}{ll}\text { Abbreviations } \\ \text { c.g } & \text { Center of gravity } \\ \text { DCV } & \text { Directional Control Valve } \\ \text { EHSA } & \text { Electro-hydraulic Servo Actuator } \\ \text { EHSV } & \text { Electro-hydraulic Servo Valve } \\ \text { ITAE } & \text { Integral Time Absolute Error }\end{array}$

PI

PID The proportional integral derivative controller

\section{Introduction}

During flight, takeoff and landing, the motion of aircraft is governed by the aerodynamic forces and is described by the flight mechanics rules. On the other hand, during taxing, the aircraft is actually a three-wheeled vehicle. The dynamic performance of this type of vehicle is of utmost importance because of their large mass and high center of gravity and above all their values and prices. The stability of these types of vehicles is very critical and needs highest considerations, particularly during on ground turning maneuvers. The dynamics of this class of vehicles during steering is governed by different aspects of its design, loading and operating parameters. Factors such as the road surface, weather conditions, steering rate and tire inflation pressure, play an important role, [2,3,4]. The handling qualities play a crucial part in vehicle safety.

The coupling between electrical and hydraulic power systems leads to much powerful steering system that saves energy and cost, [5]. Using steer by wire system combines the advantages of the hydraulic and electric systems such as the maximum power to weight ratio, high stiffness of hydraulic actuators, high controllability and precision, [6]. In the steer-by-wire system, the steering wheel is connected to the steering mechanism by an electric wire rather than a shaft. A steer-by-wire system has only electrical signals connection between the steering wheel subsystem and the steering mechanism subsystem, [7]. The elimination of the steering column shaft frees up backing space, improve crash worthiness, and increase design flexibility by allowing engineers to place the steering wheel on the middle or right or left side of the driver compartment, [8].

\section{System Description and Mathematical Modeling}

The proposed system consists of two steer pedals, two-stage electro-hydraulic servo valve, a symmetrical steering cylinder and matched control electronics including a PI controller. The EHSV is electrically controlled by the steering pedals. The steering cylinder steers the front wheel of the three-wheeled vehicle. The operating fluid under the hydraulic generator pressure $\left(\mathrm{P}_{\mathrm{P}}\right)$ is delivered to the steering EHSV, when the pilot pushes the left or the right pedal. The actuator displacement (y) is proportional to the steering pedal displacement $(\mathrm{z})$. The steering direction is determined by which pedal is depressed. The control circuit energizes the EHSV porting a pressurized hydraulic fluid to one of the cylinder chambers to steer a left or right turn accordingly. 


\subsection{Steering System Hydraulic Circuit}

The hydraulic circuit of the studied steering system is shown in Fig. 1. It consists of a hydraulic generator, a symmetrical hydraulic cylinder, (12), and an EHSV, (9) in lieu of the DCV assembly used in Part 1, [1]. The supply pressure $\left(\mathrm{P}_{\mathrm{P}}\right)$ is kept practically constant due to the effect of the pump controller, considering the high pump flow rate and the very low flow demands of the steering system.

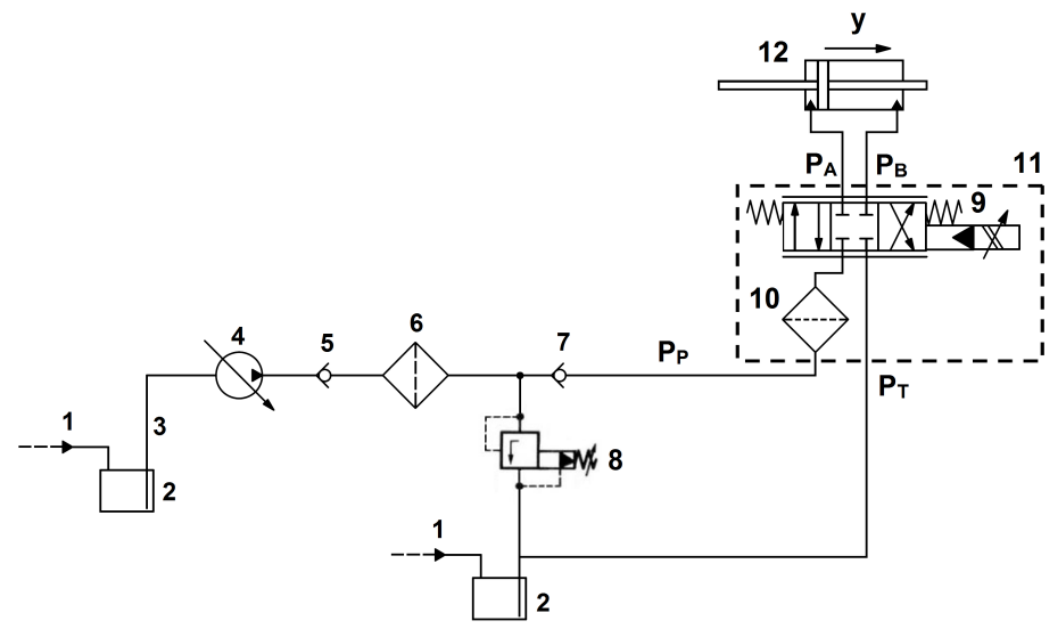

1. Tank pressurization line, 2. Tank, 3. Pump suction line, 4. Pump, 5. Check valve, 6. Filter, 7. Check valve, 8. Relief valve, 9. EHSV, 10. Inlet filter, 11. Housing, 12. Cylinder.

Fig. 1. Hydraulic circuit of the steering system incorporating EHSV

\subsection{Two-Stage Servo Valve}

Figure 2, depicts the construction of an EHSV of two stages with mechanical feedback. The first stage of the servo valve includes a torque motor of an electromagnetic type and a double nozzle flapper valve. The second stage consists of a spool valve driven hydraulically by the pressure difference developed by the flapper valve.

The operation of the two stages EHSV with mechanical feedback can be described as follows: The feedback between the second and first stages of the valve is achieved by the feedback wire (2) attached to the flapper (1) at one end and engaged in a groove in the spool (3) at its opposite end.

The displacement of the spool from null position causes a torque on the flapper (feedback torque), which opposes the armature torque. When the spool displacement is such that the feedback torque equals the armature torque, the flapper returns, almost, to its neutral position and the spool movement ceases. Actually, the flapper is slightly displaced from its neutral position. The flapper valve produces a very small pressure difference, just sufficient to equilibrate the feedback spring force. This arrangement ensures the proportionality between the spool displacement and control current.

\subsection{Mathematical Model of the Proposed Steering System}

\subsubsection{Electro-hydraulic Servo Valve}

The proposed electro-hydraulic steering system, Fig. 2, consists of a two stage electrohydraulic servo valve with mechanical feedback, a symmetrical steering cylinder (4) and 
control electronics. The dynamic behavior of the servo valve was investigated by Rabie, [9]. He developed a detailed mathematical model for the studied servo valve and proposed a simple second order transfer function governed by Eq. 1, to describe the valve behavior, [9].

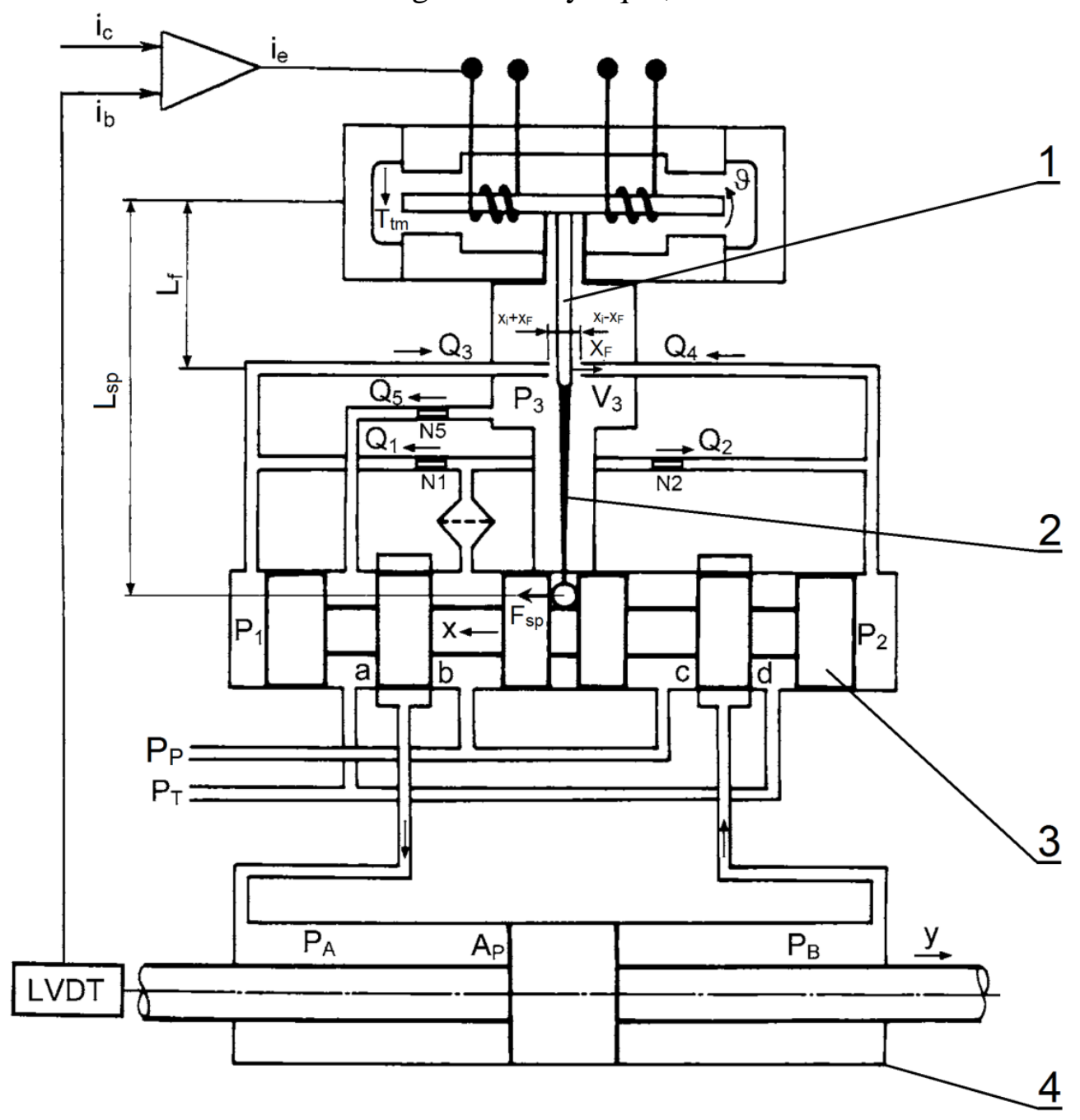

Fig. 2. Schematic of the electro-hydraulic servo actuator, [8]

$G(s)=\frac{X(s)}{I_{e}(s)}=\frac{0.020134}{0.000002 s^{2}+0.0041 s+1}$

The step response of the servo valve was calculated by the detailed model and by the transfer function; the results are plotted in Fig. 3. The results are almost coinciding and the valve response is over-damped with $10 \mathrm{~ms}$ settling time. The transfer function is therefore, used in this study to describe the servo valve dynamic behavior for its simplicity.

\subsubsection{Flow Rates through the Spool Valve}

Neglecting the effect of transmission lines, connecting the valve to the symmetrical cylinder, the flow rates through the valve restriction areas are given by Rabie, [9]:

$\mathrm{Q}_{\mathrm{a}}=\mathrm{C}_{\mathrm{d}} \mathrm{A}_{\mathrm{a}}(\mathrm{x}) \sqrt{\frac{2}{\rho}\left(\mathrm{P}_{\mathrm{A}}-\mathrm{P}_{\mathrm{T}}\right)}$ 


$$
\begin{aligned}
& Q_{b}=C_{d} A_{b}(x) \sqrt{\frac{2}{\rho}\left(P_{P}-P_{A}\right)} \\
& Q_{c}=C_{d} A_{c}(x) \sqrt{\frac{2}{\rho}\left(P_{P}-P_{B}\right)} \\
& Q_{d}=C_{d} A_{d}(x) \sqrt{\frac{2}{\rho}\left(P_{B}-P_{T}\right)}
\end{aligned}
$$

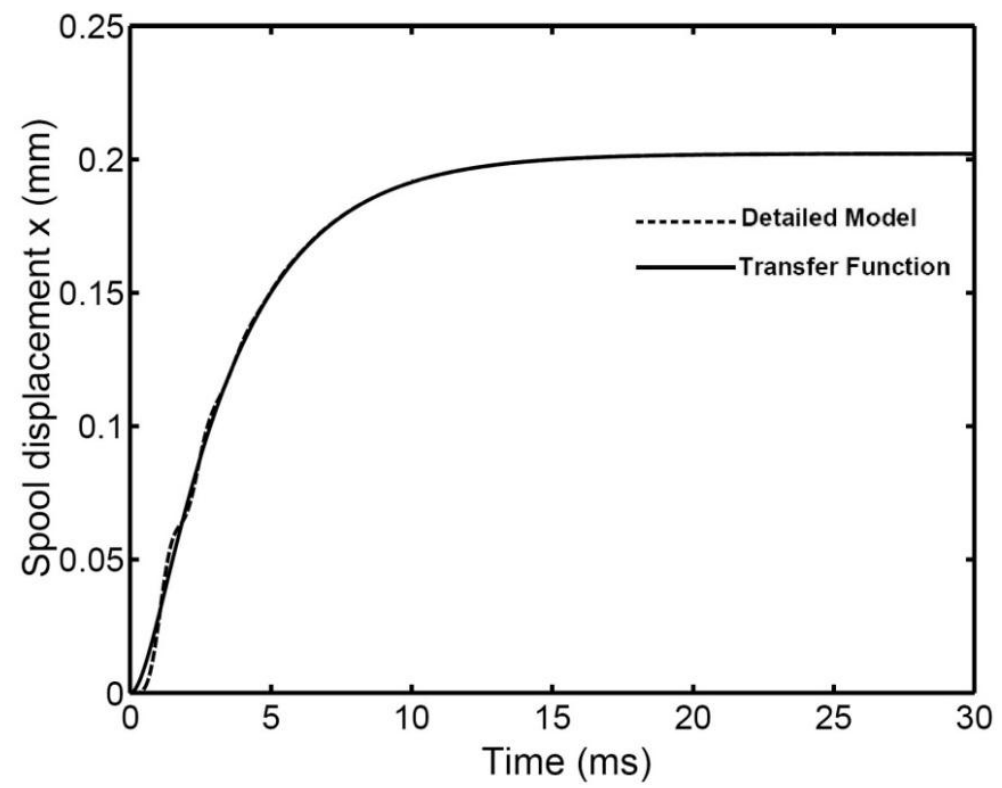

Fig. 3. Transient response of the servo valve spool displacement to a $10 \mathrm{~mA}$ step, [9]

The valve restrictions areas are given by Rabie, [9]:

$$
\begin{aligned}
& \left.\begin{array}{c}
A_{a}=A_{c}=\omega c \\
A_{b}=A_{d}=\omega \sqrt{\left(x^{2}+c^{2}\right)}
\end{array}\right\} \text { for } x \geq 0 \\
& \left.\begin{array}{c}
A_{a}=A_{c}=\omega \sqrt{\left(x^{2}+c^{2}\right)} \\
A_{b}=A_{d}=\omega c
\end{array}\right\} \text { for } x \leq 0
\end{aligned}
$$

\subsubsection{Continuity Equations Applied to the Cylinder Chambers}

Applying the continuity equation to the cylinder chambers, considering the internal leakage and neglecting the external leakage, the following equations were obtained, [9]:

$$
\begin{aligned}
& Q_{b}-Q_{a}-A_{P} \frac{d y}{d t}-\frac{\left(P_{A}-P_{B}\right)}{R_{i}}=\frac{V_{A o}+A_{P} y}{B} \frac{d P_{A}}{d t} \\
& Q_{c}-Q_{d}+A_{P} \frac{d y}{d t}+\frac{\left(P_{A}-P_{B}\right)}{R_{i}}=\frac{V_{B o}-A_{P} y}{B} \frac{d P_{B}}{d t}
\end{aligned}
$$




\subsubsection{Equation of Motion of the Piston}

The motion of the steering actuator piston under the action of pressure, viscous friction, rolling resistance forces and inertia of moving and rotating parts was previously described in Part 1, [1].

\subsubsection{Feedback Equation}

The piston displacement is picked-up by a displacement transducer and fed back to the electronic controller, which generates the corresponding error signal. The feedback loop could be described by the following equations:

$\mathrm{i}_{\mathrm{e}}=\mathrm{i}_{\mathrm{c}}-\mathrm{i}_{\mathrm{b}}$

$\mathrm{i}_{\mathrm{b}}=\mathrm{K}_{\mathrm{FB}} \mathrm{y}$

\subsubsection{PID Controller}

Generally, the PID algorithm is described as follows, [10]:

$u(t)=K\left\{e(t)+\frac{1}{T_{i}} \int_{0}^{t} e(\tau) \cdot d \tau+T_{d} \frac{d e(t)}{d t}\right\}$

The error signal $\mathrm{e}(\mathrm{t})$ is the difference between the instantaneous values of the input signal, $\mathrm{x}(\mathrm{t})$ and the feedback signal $\mathrm{f}(\mathrm{t})$; as illustrated by, Fig. 4.

$e(t)=x(t)-f(t)$

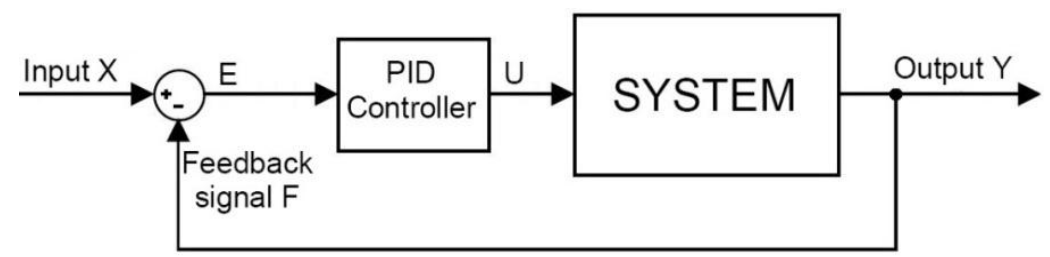

Fig. 4. Connection of the PID controller in the feedback loop, [9]

The transient responses of the EHSA, calculated using the simulation program for the electrohydraulic servo actuator incorporating, Fig. 5:

a) Simple proportional feedback controller.

b) PI controller.

This figure shows that the transient response of the EHSA with simple proportional feedback (a) shows relatively longer settling time $\left(t_{s}=309 \mathrm{~ms}\right)$ compared with the PI controller $(b)\left(t_{s}=\right.$ $33 \mathrm{~ms}$ ).

The derivative component of the PID controller had no significant effect on the transient responses of the EHSA which is sufficient reason to use the PI controller, [9]. 


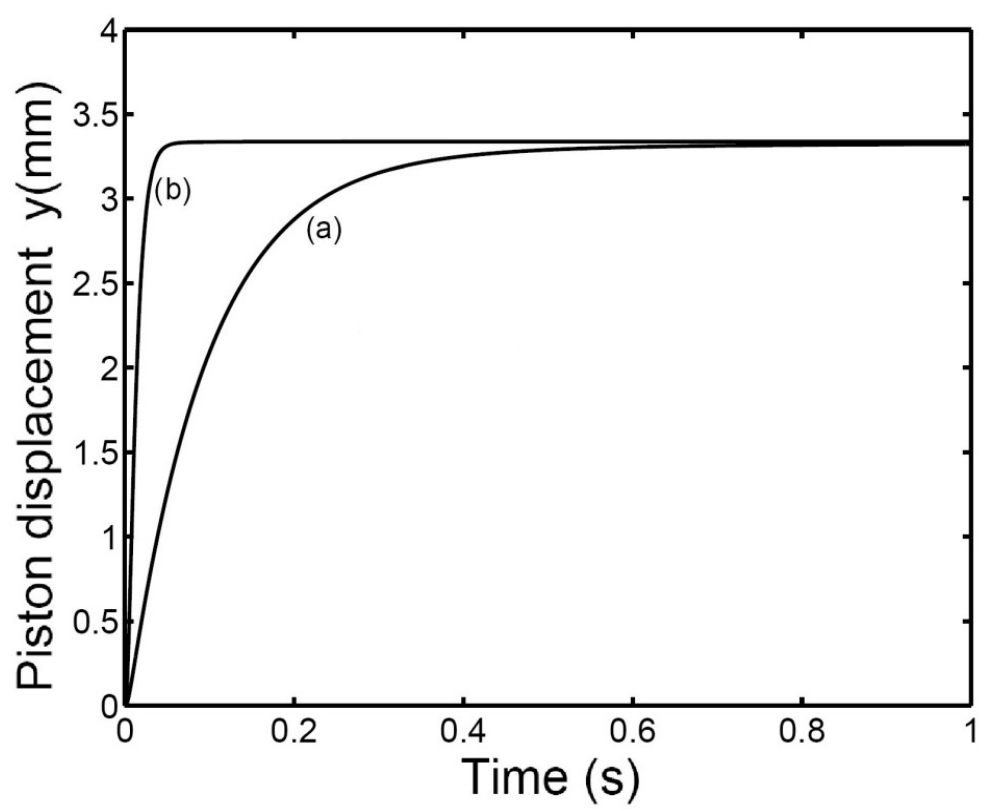

Fig. 5. Step response of the electro-hydraulic servo-actuator incorporating a $P$ or $P I$ controller, [9]

\section{Comparison between the Transient Responses of the Two Steering}

\section{Systems}

The transient response of the proposed system, Fig. 6, was calculated and compared with that of the original steering system by using MATLAB-SIMULINK.

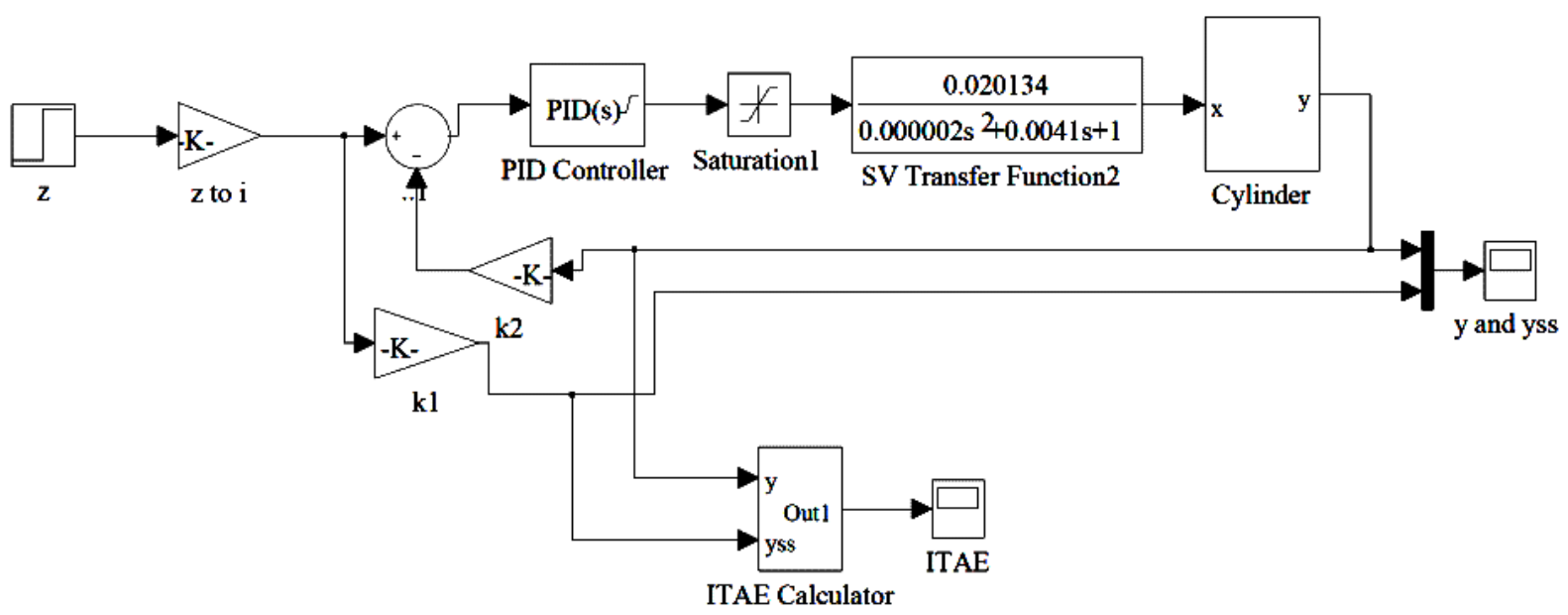

Fig. 6. Simulation block diagram of the Steering system with PI Controller Integral of time absolute error ITAE

The comparison, Fig. 7, showed that both systems presented almost the same response except a slight delay of the DCV system within $23 \mathrm{~ms}$ (the system response duration was within 3 seconds) and a negligible overshoot within $1.5 \%$. The two systems have the same slope because of limiting the maximum input current to the steering speed to satisfy an important safety requirement. 
The EHSV is much more expensive but it has the following advantages: Practically a negligible time delay and no response overshoot. But if compared with the original system, it is of lower reliability and higher cost.

The original steering system is much simpler, less expensive and has relatively higher reliability. However, it presents slight time delay and slight over shoot compared with the EHSV steering system.

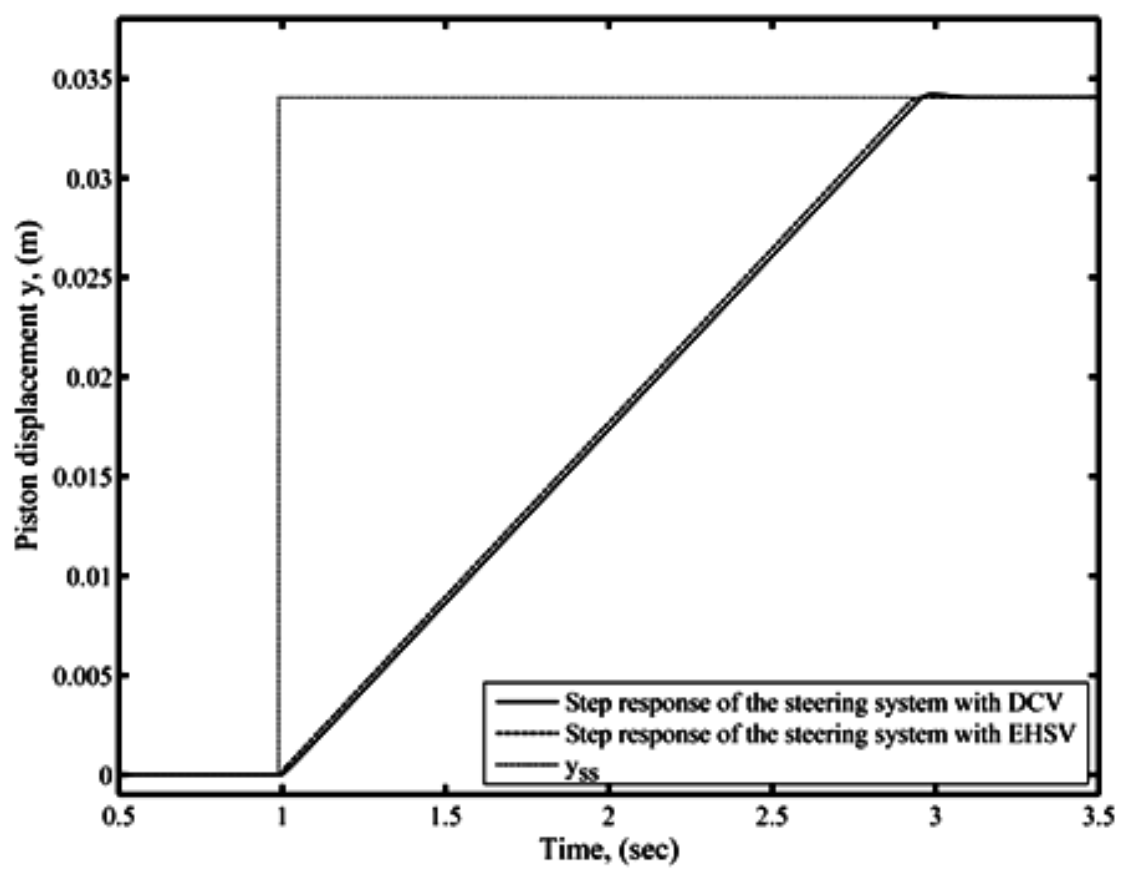

Fig. 7. Comparison between the step response of the loaded steering system incorporating the EHSV and the DCV assembly

\section{Mathematical Handling Model of the Vehicle Dynamics}

\subsection{Estimation of the Vehicle Rollover Speed Threshold and Road Adhesion Limitation}

In this section, preliminary estimations of the vehicle rollover speed and the speed at which side skid might occur are first calculated as a guide line for studying the vehicle dynamics when negotiating a turn.

The value of the centrifugal force $\left(\mathrm{F}_{\mathrm{c}}\right)$ of a 3-wheel vehicle is slightly complex and will involve the longitudinal placement of the c.g as well as its height $\left(\mathrm{h}_{\mathrm{cg}}\right)$, and the vehicle track $[11,12,13]$. Fig. 8 , shows a 3 -wheel vehicle during a right turn with the resulting centrifugal force and its reactions at the tire contact patches in $\mathrm{x}_{\mathrm{cg}}-\mathrm{y}_{\mathrm{cg}}$ plane. The turning radius of the vehicle c.g, $\left(\mathrm{R}_{\mathrm{cg}}\right)$ when the front wheel is given a steer angle $(\delta)$ is obtained from the geometry of Fig. 8 and it is equal to:

$\mathrm{R}_{\mathrm{cg}}=\sqrt{\mathrm{l}_{2}{ }^{2}+\mathrm{R}_{1}{ }^{2}}$, where $\mathrm{R}_{1}=\frac{\mathrm{l}}{\tan \delta}$

Figure 9, shows the dynamic forces applied on the vehicle and tire reactions in the vertical direction. The corresponding threshold rollover vehicle speed is obtained by taking the 
moments about the line joining the centers of the contact batches of the front tire and the outer rear tire (vehicle rollover line, OF). The condition for rollover speed is that the vertical reaction of the inner rear wheel vanishes. The governing equation is given below, Eq. 15 .

$\mathrm{jW}=\frac{\mathrm{W}}{\mathrm{g}} \mathrm{h}_{\mathrm{cg}} \frac{\mathrm{v}_{\mathrm{xcg}}^{2}}{\mathrm{R}_{\mathrm{cg}}} \cos \varepsilon$

Rearranging the above equation gives the vehicle rollover speed $\left(\mathrm{v}_{\text {roll }}\right)$ :

$\mathrm{v}_{\text {roll }}=\sqrt{\frac{\mathrm{jg}}{\mathrm{h}_{\mathrm{cg}}}} \sqrt{\frac{\mathrm{R}_{\mathrm{cg}}}{\cos \varepsilon}}, \quad \mathrm{j}=\frac{0.5 \mathrm{bl}_{1}}{\sqrt{\mathrm{l}^{2}+\left(\frac{\mathrm{b}}{2}\right)^{2}}}$

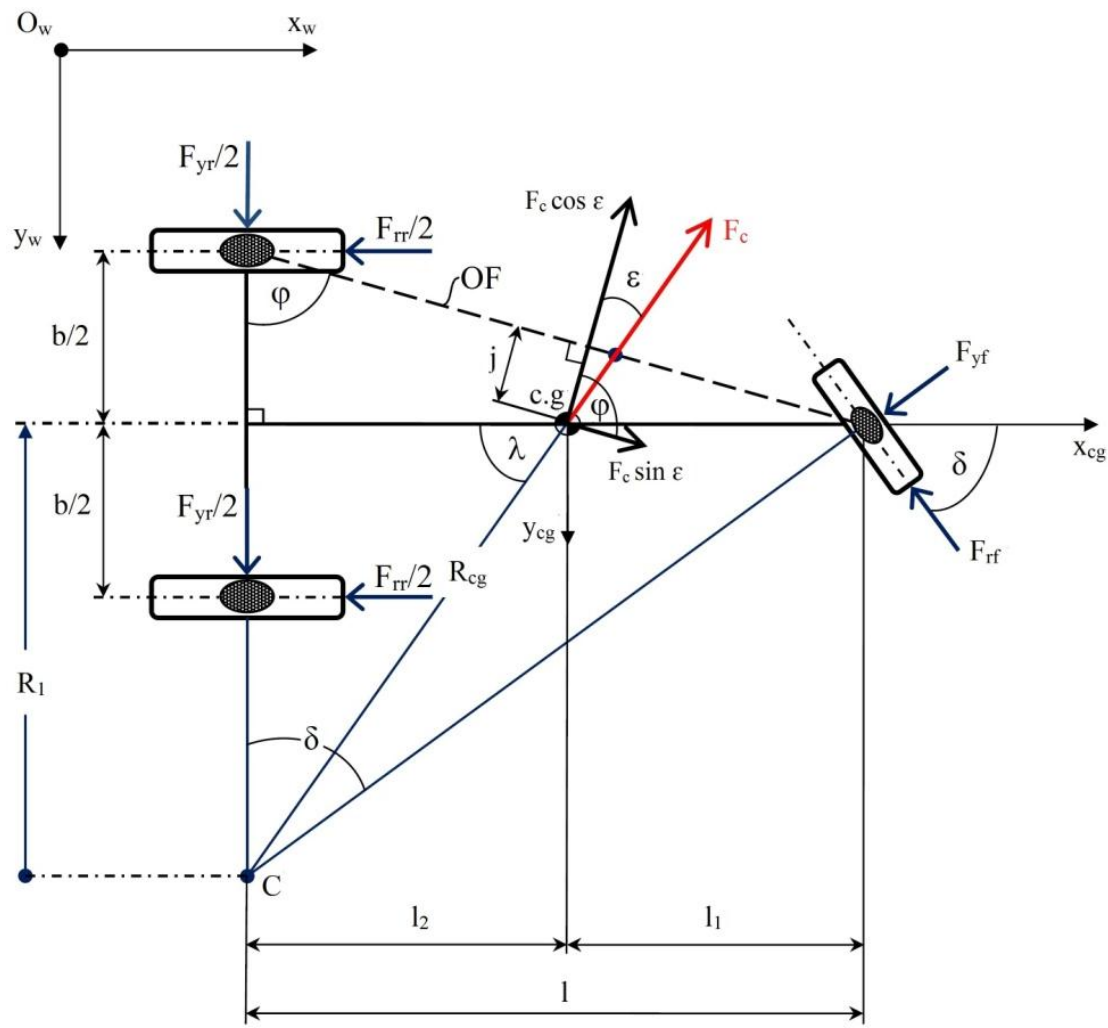

Fig. 8. A 3-wheel vehicle rollover model in $x_{\mathrm{cg}}-y_{\mathrm{cg}}$ plane

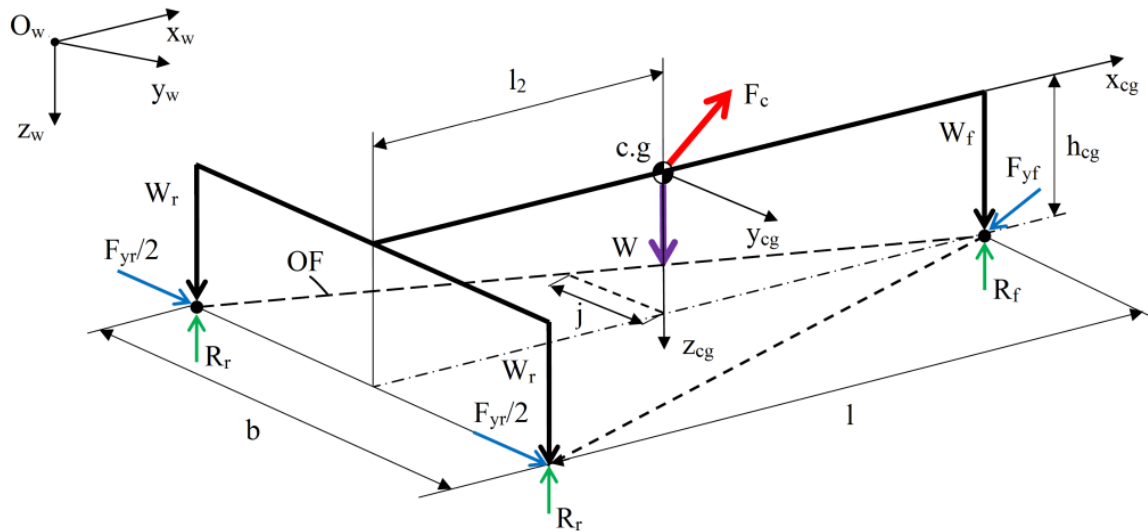

Fig. 9. A 3-wheel vehicle rollover 3-D model 


$$
\begin{aligned}
& \varphi=\tan ^{-1}\left(\frac{2 \mathrm{l}}{\mathrm{b}}\right)=\text { constant } \\
& \lambda=\cos ^{-1}\left(\frac{\mathrm{l}_{2}}{\mathrm{R}_{\mathrm{cg}}}\right)=\tan ^{-1}\left(\frac{\mathrm{R}_{1}}{\mathrm{l}_{2}}\right) \\
& \varepsilon=\varphi-\lambda
\end{aligned}
$$

The vehicle turning radius, $\left(\mathrm{R}_{\mathrm{cg}}\right)$ and the rollover speed, $\left(\mathrm{v}_{\mathrm{roll}}\right)$ are calculated versus the front wheel steer angle (d) as shown in Fig. 10, which is based on the actual parameter values of the vehicle under investigation in this thesis. Further, this figure can help in predicting the required steer angle value and the vehicle threshold rollover speed if the vehicle is to negotiate a curved road with constant radius. This is indicated on the graph by the dashed lines. For radius value, $\left(\mathrm{R}_{\mathrm{cg}}=6.43 \mathrm{~m}\right)$, resulting in the required steer angle, $\left(\mathrm{d}=32.21^{\circ}\right)$, and rollover speed, $\left(\mathrm{v}_{\text {roll }}=5.09 \mathrm{~m} / \mathrm{s}=18.33 \mathrm{~km} / \mathrm{h}\right)$.

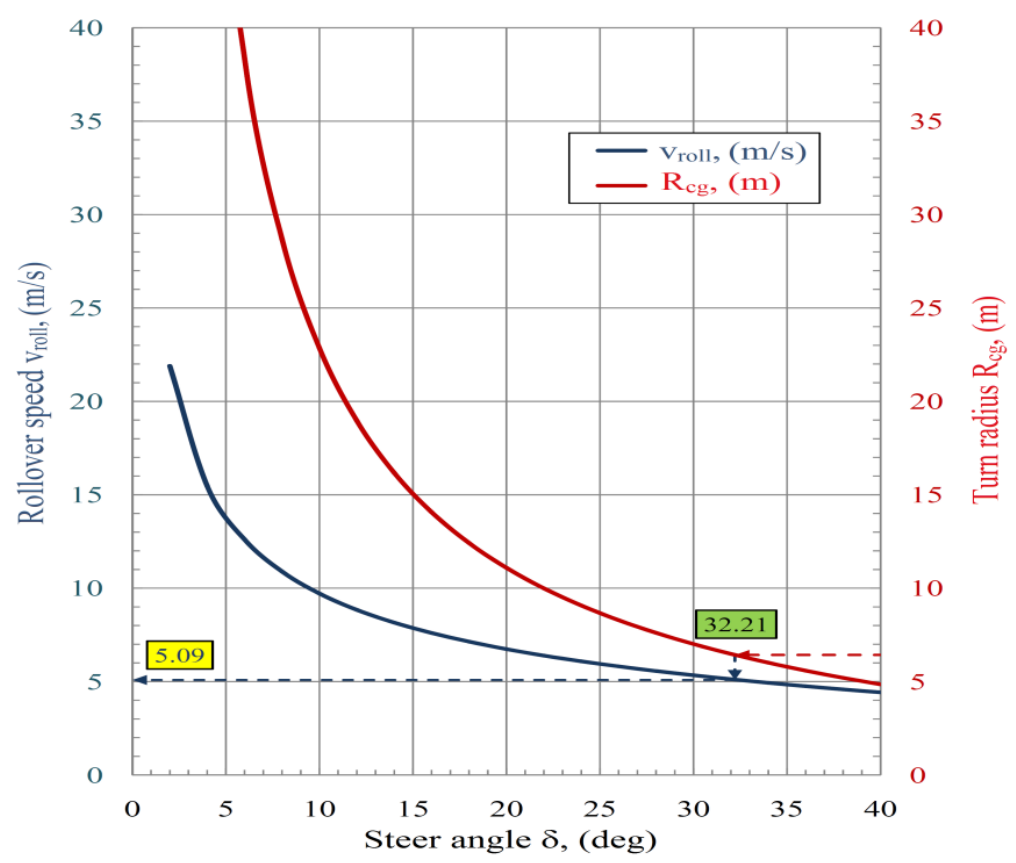

Fig. 10. Relation between rollover speed, turning radius and the steer angle

It worth mentioning here that, the threshold vehicle/road adhesion coefficient, $\mu$ is obtained from the following equation:

$\mathrm{F}_{\mathrm{c}}=\mu \mathrm{W}=\frac{\mathrm{W}}{\mathrm{g}} \frac{\mathrm{v}_{\text {roll }}^{2}}{\mathrm{R}_{\mathrm{cg}}}$, i. e., $\quad \mu=\frac{\left(\mathrm{v}_{\text {roll }}^{2} / \mathrm{R}_{\mathrm{cg}}\right)}{\mathrm{g}}=\frac{\mathrm{a}_{\mathrm{ycg}}}{\mathrm{g}}$

Considering the steer angle, $\mathrm{d}=32.21^{\circ}$ the corresponding rollover speed, $\mathrm{v}_{\text {roll }}=5.09 \mathrm{~m} / \mathrm{s}$, and radius, $R_{\mathrm{cg}}=6.43 \mathrm{~m}$ are obtained from Fig. 10. Inserting these values in the Eq. 21 yields the threshold adhesion, $\mathrm{m}=0.411$. Similarly, considering $\mathrm{d}=2^{\circ}$ and corresponding $\mathrm{v}_{\text {roll }}=21.9$ $\mathrm{m} / \mathrm{s}$ and $\mathrm{R}_{\mathrm{cg}}=115.41 \mathrm{~m}$ gives the threshold adhesion, $\mathrm{m}=0.424$. The calculated two values of $\mathrm{m}$ are less than the value measured experimentally by a drag test for the wheel using force gauge on the conventional maneuvering area of the vehicle. The adhesion coefficient, $\mathrm{m}_{\mathrm{ms}}$ is obtained from Eq. 21. 
adhesion coefficient, $\mu_{\mathrm{ms}}=\frac{\mathrm{drag} \text { force }}{\text { wheel weight }}=\frac{97.89}{124.59}=0.786$

Since it is preferable, form safety point of view, that the vehicle side skid to occur before the rollover; and $\mathrm{m}_{\mathrm{ms}}>\mathrm{m}$ utmost care must be taken during the maneuver of the vehicle considered in this investigation to avoid the catastrophic rollover accidents.

\subsection{Transient Handling Model}

Between the application of steering input and the attainment of steady state motion, the vehicle is in a transient state. The behavior of the vehicle in this period is usually referred to as "transient response characteristics". The overall handling quality of a vehicle depends, to a great extent, on its transient behavior. The optimum transient response of a vehicle is that, which has the fastest response with a minimum of oscillation in the process of approaching the steady-state motion, [14].

The handling bicycle model is utilized in the present study to establish the transient response of the vehicle using axes fixed to vehicle body; $\left(\mathrm{x}_{\mathrm{cg}}\right)$ and $\left(\mathrm{y}_{\mathrm{cg}}\right)$. The acceleration components of the c.g along these axes have established in, [14].

$\mathrm{a}_{\mathrm{xcg}}=\dot{\mathrm{v}}_{\mathrm{xcg}}-\mathrm{v}_{\mathrm{ycg}} \Omega_{\mathrm{z}} \quad, \mathrm{a}_{\mathrm{ycg}}=\dot{\mathrm{v}}_{\mathrm{ycg}}+\mathrm{v}_{\mathrm{xcg}} \Omega_{\mathrm{z}}$

Figures 11 and 12 show the kinematics and kinetics of the simplified vehicle model during a transient motion. Examination of these figures together with Eq. 22, the three equations of motion of the vehicle can be obtained as detailed in the following:

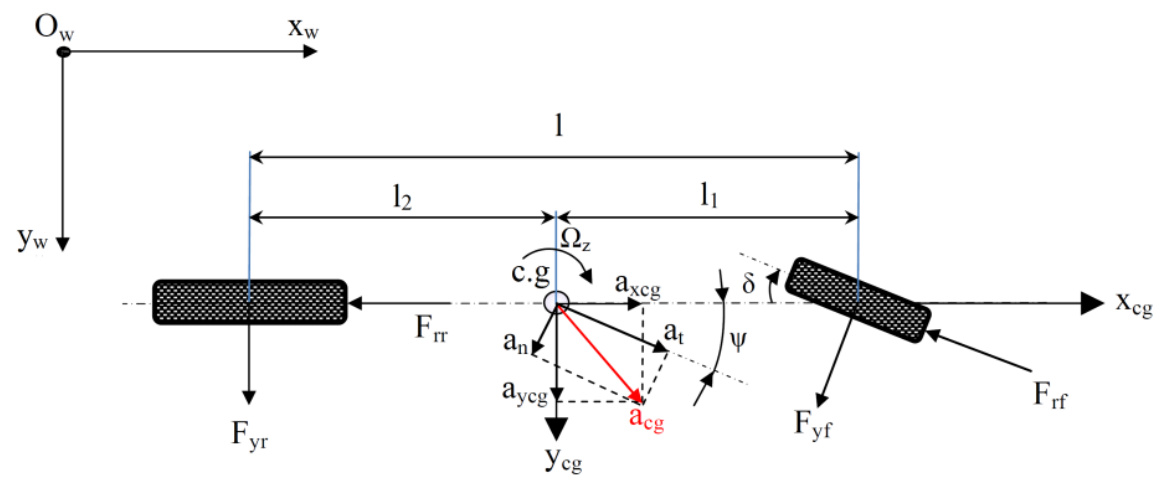

Fig. 11. Kinetics for the simplified vehicle model during transient motions, [14]

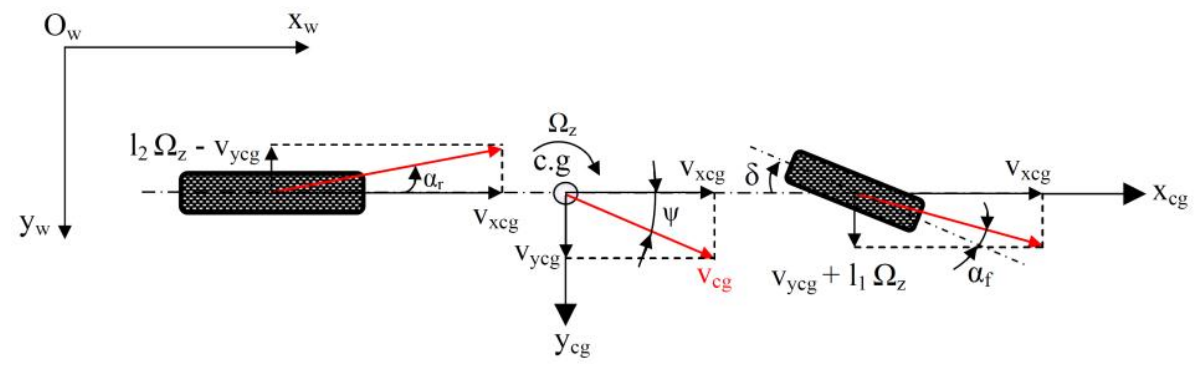

Fig. 12. Kinematics for the simplified vehicle model during transient motions, [14]

$$
\begin{aligned}
& \mathrm{m}\left(\dot{\mathrm{v}}_{\mathrm{xcg}}-\mathrm{v}_{\mathrm{ycg}} \Omega_{\mathrm{z}}\right)=\mathrm{T}_{\mathrm{th}}-\mathrm{F}_{\mathrm{rr}}-\mathrm{F}_{\mathrm{rf}} \cos \delta-\mathrm{F}_{\mathrm{yf}} \sin \delta \\
& \mathrm{m}\left(\dot{\mathrm{v}}_{\mathrm{ycg}}+\mathrm{v}_{\mathrm{xcg}} \Omega_{\mathrm{z}}\right)=\mathrm{F}_{\mathrm{SF}}+\mathrm{F}_{\mathrm{yr}}+\mathrm{F}_{\mathrm{yf}} \cos \delta-\mathrm{F}_{\mathrm{rf}} \sin \delta
\end{aligned}
$$


$\mathrm{I}_{\mathrm{z}} \dot{\Omega}_{\mathrm{z}}=\mathrm{F}_{\mathrm{yf}} \mathrm{l}_{1} \cos \delta-\mathrm{F}_{\mathrm{yr}} \mathrm{l}_{2}-\mathrm{F}_{\mathrm{rf}} \mathrm{l}_{1} \sin \delta$

In deriving the above equations, it is assumed that the vehicle body is symmetric about the longitudinal plane and that roll motion of the vehicle body is neglected, [14].

The slip angles $\left(\alpha_{\mathrm{f}}\right)$ and $\left(\alpha_{\mathrm{r}}\right)$, can be defined in terms of the vehicle motion variables $\left(\Omega_{\mathrm{z}}\right)$ and $\left(\mathrm{v}_{\mathrm{ycg}}\right)$. Referring to Fig. 12, and using the usual small angle assumptions.

$$
\begin{aligned}
& \alpha_{\mathrm{f}}=\delta-\left[\frac{\mathrm{v}_{\mathrm{ycg}}+\mathrm{l}_{1} \Omega_{\mathrm{z}}}{\mathrm{v}_{\mathrm{xcg}}}\right] \\
& \alpha_{\mathrm{r}}=\frac{\Omega_{\mathrm{z}} \mathrm{l}_{2}-\mathrm{v}_{\mathrm{ycg}}}{\mathrm{v}_{\mathrm{xcg}}}
\end{aligned}
$$

The lateral forces acting on the front and rear tires are a function of the corresponding slip angle and cornering stiffness, and are expressed by Eq. 28 for single tire in the front and by Eq. 29 for two tires in the rear:

$$
\begin{aligned}
& \mathrm{F}_{\mathrm{yf}}=\mathrm{C}_{\alpha \mathrm{f}} \alpha_{\mathrm{f}} \\
& \mathrm{F}_{\mathrm{yr}}=2 \mathrm{C}_{\alpha \mathrm{r}} \alpha_{\mathrm{r}} \\
& \mathrm{F}_{\mathrm{rf}}=\mathrm{f}_{\mathrm{rr}} \mathrm{W}_{\mathrm{f}} \\
& \mathrm{F}_{\mathrm{rr}}=2 \mathrm{f}_{\mathrm{rr}} \mathrm{W}_{\mathrm{r}}
\end{aligned}
$$

The engine thrust value is adjusted to be:

$\mathrm{T}_{\mathrm{th}}=\mathrm{F}_{\mathrm{rr}}+\mathrm{F}_{\mathrm{rf}} \cos \delta$

In the above equations, (d) represents the steer angle of the front wheel as a function of time. If, in addition to the steer angle, external forces or moments, are acting on the vehicle, they should be added to the right-hand side of Eqs. 23 through 25 as input variables. Solution of the these equations yields the variation of $\left(\mathrm{x}_{\mathrm{cg}}(\mathrm{t})\right),\left(\mathrm{y}_{\mathrm{cg}}(\mathrm{t})\right)$ and $\Omega_{\mathrm{z}}(\mathrm{t})$ related to the axes fixed to the vehicle c.g, [14].

However, the trajectory of the vehicle c.g, and orientation of its longitudinal axis related to fixed axes in space (World axes) are of significant importance. To obtain the solution of the three differential equations of motion related to the world axes, the following well established transformation matrix is incorporated in the solution, $[15,16]$.

$$
\left[\begin{array}{c}
\mathrm{v}_{\mathrm{xw}} \\
\mathrm{v}_{\mathrm{yw}} \\
\Omega_{\mathrm{zw}}
\end{array}\right]=\left[\begin{array}{ccc}
\cos \psi & -\sin \psi & 0 \\
\sin \psi & \cos \psi & 0 \\
0 & 0 & 1
\end{array}\right]\left[\begin{array}{c}
\mathrm{v}_{\mathrm{xcg}} \\
\mathrm{v}_{\mathrm{ycg}} \\
\Omega_{\mathrm{z}}
\end{array}\right]
$$

The position of the vehicle c.g, $\left(\mathrm{x}_{\mathrm{w}}(\mathrm{t}), \mathrm{y}_{\mathrm{w}}(\mathrm{t})\right)$ can be obtained in the world axis from the following Eqs. 34 and 35, while the heading angle of the longitudinal axis $(\psi(t))$ can be obtained from Eq. 36 as follows: 
$x_{w}(t)=\int v_{x w} \cdot d t$

$y_{w}(t)=\int v_{y w} \cdot d t$

$\psi(t)=\int \Omega_{\mathrm{zw}} \cdot \mathrm{dt}$

In analyzing the transient response, the inertia properties of the vehicle must be taken into consideration. During a turning maneuver, the vehicle is in translation as well as in rotation. The solution method adopted here utilizes MATLAB-SIMULINK.

The values of the vehicle mass equals $9295.44 \mathrm{~kg}$ and vehicle yaw mass moment of inertia equals $85552.10 \mathrm{~kg} \cdot \mathrm{m}^{2}$ are used as inputs to the simulation model of the vehicle obtained from, [17,18]. The tires cornering stiffness (bias-ply) are taken approximately $12 \%$ of the load on the tire, [19].

$$
\begin{aligned}
& \mathrm{C}_{\alpha_{\mathrm{f}}}=0.12 \times \mathrm{Wf} \times\left(\frac{180}{\pi}\right)=105.771 \mathrm{kN} / \mathrm{rad} \\
& \mathrm{C}_{\alpha_{\mathrm{r}}}=0.12 \times \mathrm{Wr} \times\left(\frac{180}{\pi}\right)=260.713 \mathrm{kN} / \mathrm{rad}
\end{aligned}
$$

The understeer coefficient, $\left(\mathrm{K}_{\mathrm{us}}\right)$ is given by:

$\mathrm{K}_{\mathrm{us}}=\left(\frac{\mathrm{Wf}}{\mathrm{C}_{\alpha_{\mathrm{f}}}}-\frac{\mathrm{Wr}}{\mathrm{C}_{\alpha_{\mathrm{r}}}}\right)=+0.0001 \mathrm{rad}$.

Since the under steer coefficient $\left(\mathrm{K}_{\mathrm{us}}\right)$ is positive, therefore the vehicle is considered as an understeer vehicle having a characteristic speed, $\left(\mathrm{v}_{\text {char }}\right)$ evaluated by Eq. 40 :

$\mathrm{v}_{\text {char }}=\sqrt{\frac{\mathrm{gl}}{\mathrm{K}_{\mathrm{us}}}}=628.76 \mathrm{~m} / \mathrm{s}=2263 \mathrm{~km} / \mathrm{h}$

\subsection{Comparison between the Transient Responses of the Two Steering Systems}

Fig. 16, shows the transient responses of the vehicle trajectories accomplished by step input of the steer pedal, $\mathrm{z}=1.27 \mathrm{~cm}$, at delay time, $\mathrm{t}_{\mathrm{o}}=1 \mathrm{~s}$, for the steering system equipped with the DCV assembly and for the one equipped with the proposed EHSV. The vehicle started this maneuver with initial velocity equals $4.5 \mathrm{~m} / \mathrm{s}$.

It is obvious that the final steady state responses are circular paths, but with slight difference between the two centers of rotations. The difference amounted to only $0.035 \mathrm{~m}$, and this can be attributed to the previously mentioned time delay in the steering system incorporating the 
DCV assembly. The $0.035 \mathrm{~m}$ shift of the center of rotation is in fact in the forward motion direction (right) compared with that of the system incorporating EHSV.

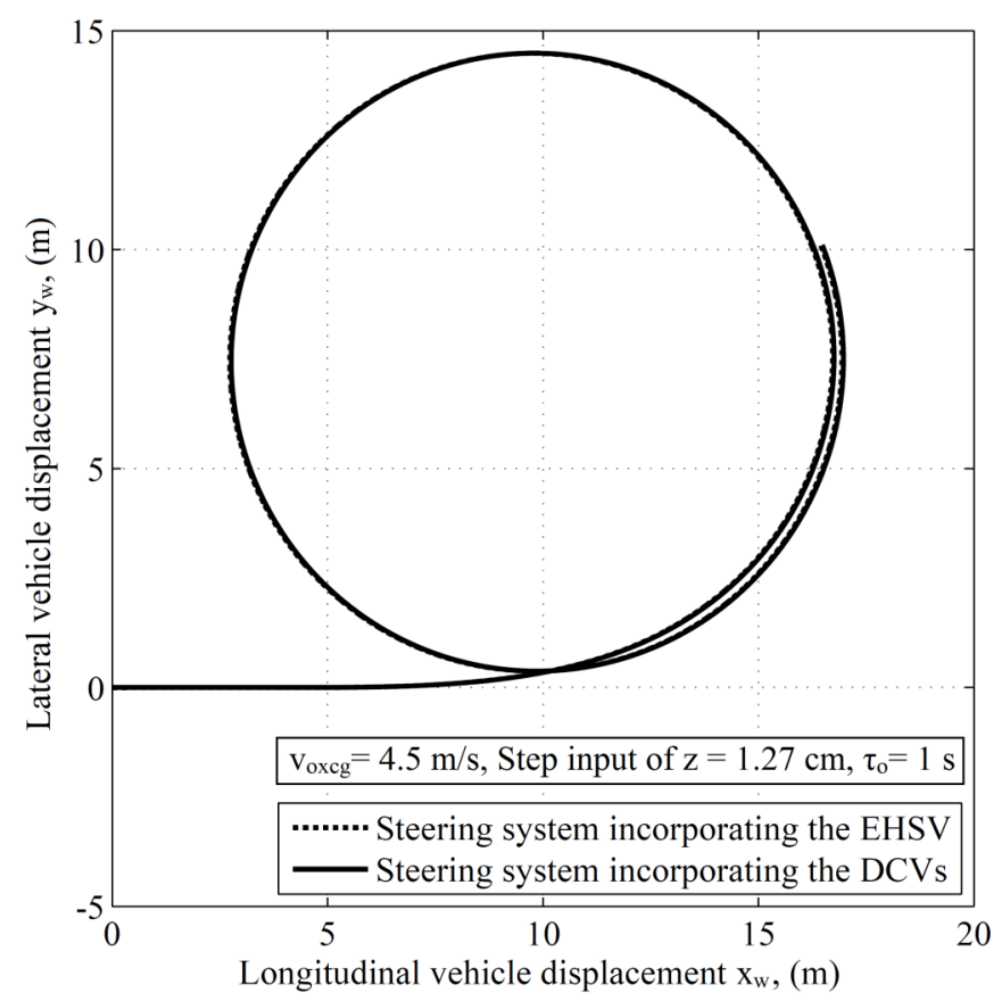

Fig. 16. Comparison between the effects of utilizing an EHSV in lieu of the steering DCV assembly on the transient response of the vehicle trajectories

\subsection{Handling Dynamics Analysis of the Vehicle Incorporating EHSV}

In this section a parametric study is carried out utilizing the developed handling model to show the effects of the tire cornering stiffness, side wind and vehicle speed on the yaw velocity response of the vehicle.

\subsubsection{Effects of Tire Cornering Stiffness}

It have been well established in the literature that the cornering stiffness of the tire is noticeably dependent on the inflation pressure and applied vertical load. Therefore, three values of the cornering stiffness of the rear tires are used to examine the effect of such parameter on the yaw velocity response of the vehicle. A nominal stiffness value is considered together with $\pm 25 \%$ variations of this value. The examination is carried out at constant vehicle forward speed of $14 \mathrm{~m} / \mathrm{s}(50.4 \mathrm{~km} / \mathrm{h})$ and step input function of steer pedal. The response curves are shown in, Fig. 17.

It worth mentioning here that the vehicle was nominally slightly under-steer but decreasing the rear tires cornering stiffness by $25 \%$ (i.e., stiffness $=0.75 \times \mathrm{C}_{\alpha \mathrm{r}}$ ) results in the vehicle becoming over-steer. This is clear from the new value of $\left(\mathrm{K}_{\mathrm{us}}\right)$ becoming negative and equal to $-0.0483 \mathrm{rad}$. On the other hand, increasing the stiffness by $25 \%$ (i.e., stiffness $=1.25 \times \mathrm{C}_{\alpha \mathrm{r}}$ ) results in the vehicle becoming more under-steer with $\mathrm{K}_{\mathrm{us}}=+0.0292 \mathrm{rad}$. 


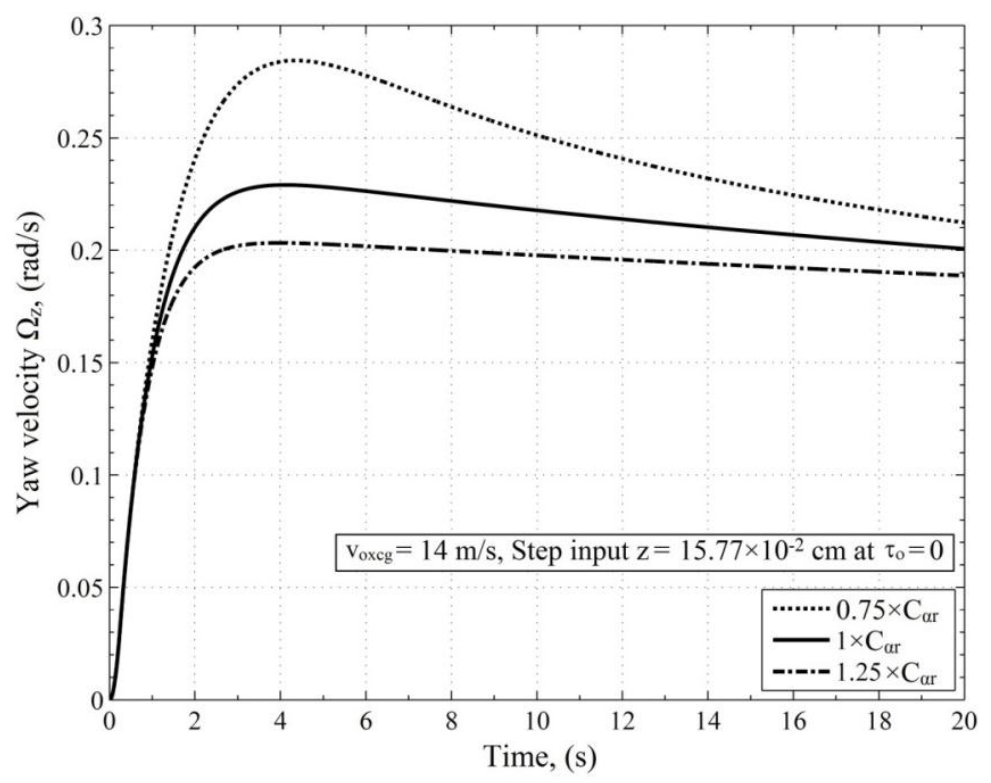

Fig. 17. Effect of rear tires cornering stiffness on yaw velocity response to a step input of steer pedal displacement

Moreover, the effects of the three values of the cornering stiffness due to a step input of side force (resulting from side wind) followed by a step input of pedal displacement are shown in Fig. 18.

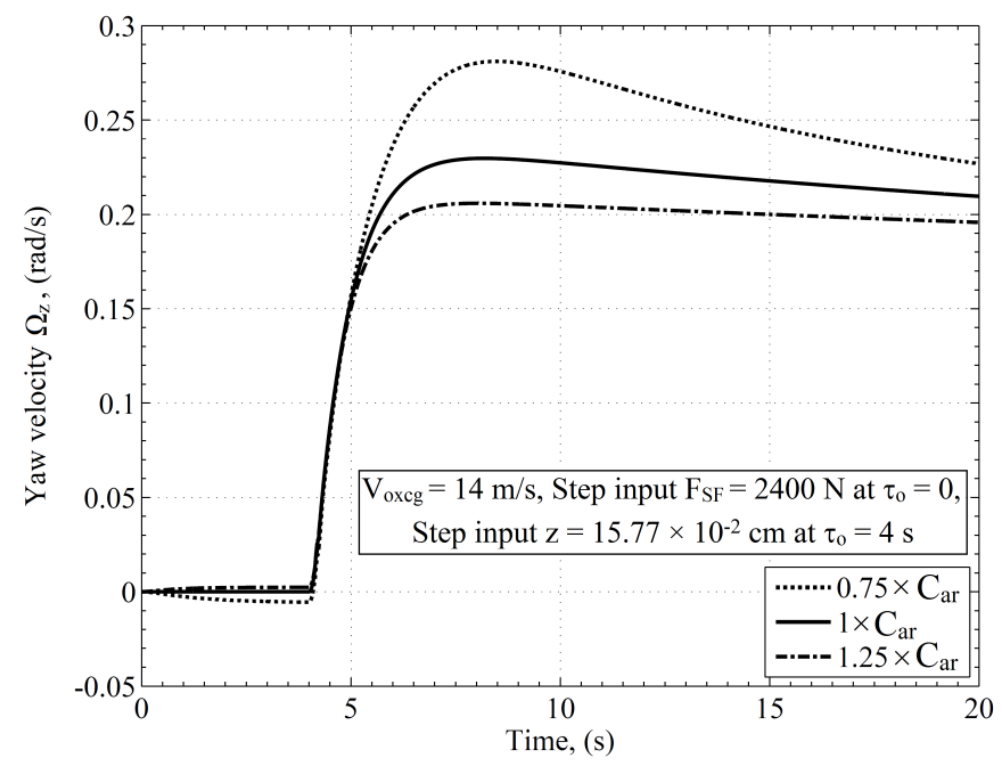

Fig. 18. Effect of rear tires cornering stiffness on yaw velocity response to a step input of side force followed by 4 seconds delayed step input of steer pedal displacement

The simulation results in Fig. 19, shows that for the slight understeer behavior of the studied vehicle if a step input of side force is applied on its c.g its yaw velocity increases in the positive direction up to $8.8 \times 10^{-6} \mathrm{rad} / \mathrm{s}$; i.e., it turns away slightly from the side force.

By decreasing the cornering stiffness of the rear tires by $25 \%$ the vehicle behavior will change from understeer to oversteer that if a step input of side force is applied on its c.g its yaw velocity increases in the negative direction; i.e., it turns toward the side force.

By increasing the cornering stiffness of the rear tires by $25 \%$ the vehicle understeer behavior increases if a step input of side force is applied on its c.g its yaw velocity increases in the 
positive direction; i.e., it turns away from the side force and this completely agrees with Wong, [14].

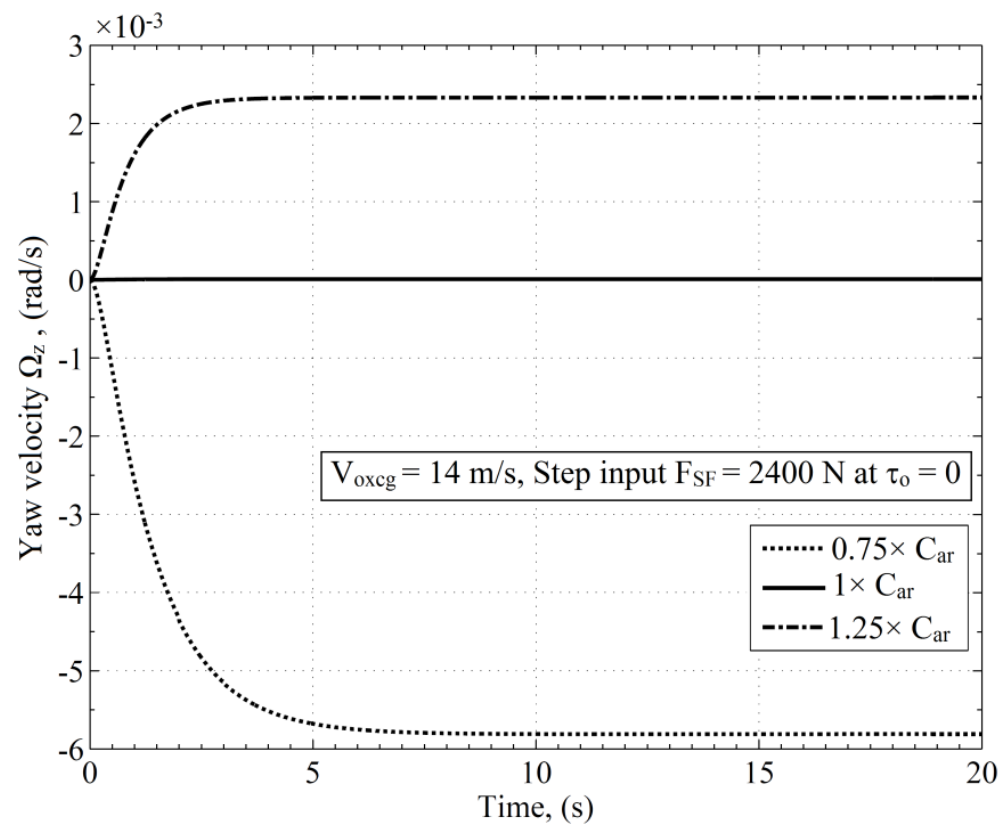

Fig. 19. Effect of rear tires cornering stiffness on yaw velocity response due to a step input of side force

\subsubsection{Effects of Vehicle Speed}

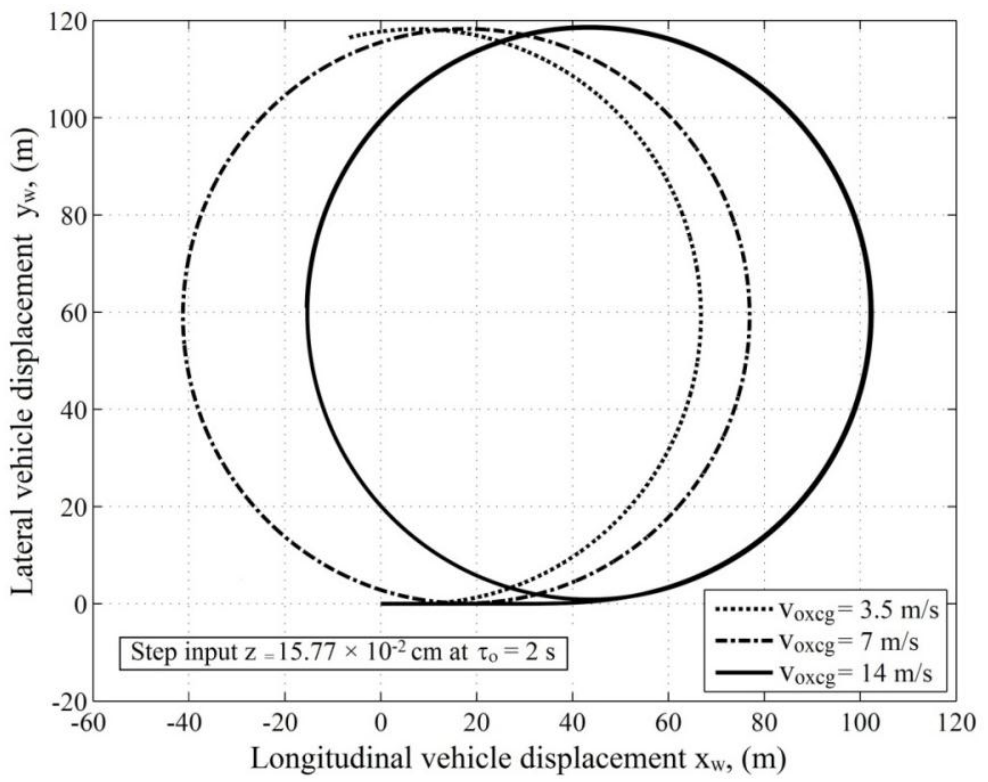

Fig. 20. Effect of vehicle speed on the vehicle trajectory during circle maneuver

Effects of the vehicle forward speed are shown in, Fig. 20, due to a step input of steer pedal. Examining the response curves reveals that the final turning radius is almost equal for the three chosen velocity but the vehicle paths to reach the steady state responses are different. That is the instantaneous turning center is shifted in the direction of the initial vehicle motion as the vehicle speed increases. Considering the nominal maneuver speed is $7 \mathrm{~m} / \mathrm{s}$, doubling this speed to $14 \mathrm{~m} / \mathrm{s}$ shifted the instantaneous turning center by $25.17 \mathrm{~m}$ to the right, while decreasing the speed to $3.5 \mathrm{~m} / \mathrm{s}$ shifted the instantaneous turning center by $10.15 \mathrm{~m}$ to the left. This indicates the importance of the vehicle speed at which maneuvering takes place. 


\section{Conclusions}

The paper is dedicated to investigate the effects of utilizing an electro-hydraulic servo valve EHSV as an alternate replacement to a direction control valve DCV assembly in a steering system for a three-wheel vehicle on the dynamic handling performance of the vehicle during road maneuvers.

The original studied system included a directional control valve DCV assembly, incorporating three $3 / 2$ directional control valves. The paper included a detailed description of the basic components of the electro-hydraulic steering system used to control the three-wheel vehicle and the mechanisms constituting the system. A nonlinear mathematical model describing the static and dynamic performance of the electro-hydraulic system and the included mechanisms is deduced. The simulation programs using MATLAB-SIMULINK have been developed based on the deduced mathematical model. The step response of the system also has been calculated, presented and analyzed. The flow characteristics of the directional control valves were evaluated experimentally in Part 1, [1]. The simulation results showed good agreement with the experimental results which validates the simulation program in the steady state operating mode.

The investigation included a proposal for the improvement of the steering system by replacing the DCV assembly by an EHSV. The transient performance of the steering system incorporating the EHSV was studied by deducing a describing mathematical model and developing a computer simulation program.

One of the main outcomes reached in this study is the capability of tuning the electrohydraulic servo valve design parameters in order to achieve an alternative replacement to the DCV assembly satisfying a highly matched accuracy responses for the new proposed system.

From safety point of view during negotiating a turn, the threshold of the vehicle rollover speed and road adhesion limitations have been examined and a design chart is obtained relating the steer angle, vehicle threshold rollover speed and turning radius. That is by decreasing the steer angle from $\left(32.21^{\circ}\right)$ to $\left(2^{\circ}\right)$ the allowable turn radius increases from $(6.43$ $\mathrm{m})$ to $(115.41 \mathrm{~m})$ and that result in increasing the rollover speed from $(5.09 \mathrm{~m} / \mathrm{s})$ to $(21.9 \mathrm{~m} / \mathrm{s})$.

To avoid the occurrence of the rollover of this particular vehicle before side skid the threshold of the road adhesion must not exceed the value of 0.411. Since the measured value of adhesion, $\mathrm{m}_{\mathrm{ms}}=0.786$ of the road where the present vehicle in usually operated, the pilot must be aware of the fact if he exceeds a defined speed the vehicle will rollover. Such roll over speed is related to the road curvature as shown on the aforementioned design chart.

The transient response of the proposed system was obtained and compared with that of the original system. The comparison showed that both systems presented almost the same response except a slight delay of the DCV system within $23 \mathrm{~ms}$ (the system response duration was within 3 seconds) and a negligible overshoot within $1.5 \%$. The previously mentioned time delay in the steering system incorporating the DCV causes a $0.035 \mathrm{~m}$ shift of the vehicle's trajectory center of rotation towards the forward direction (right) with respect to that of the system incorporating EHSV during the vehicle response due to steer pedal step input.

Decreasing the inflation pressure of the rear tires to decrease the cornering stiffness coefficient by $25 \%$ the vehicle behavior will change from under-steer $\left(\mathrm{K}_{\mathrm{us}}=+0.0001 \mathrm{rad}\right)$ to over-steer $\left(\mathrm{K}_{\mathrm{us}}=-0.0483 \mathrm{rad}\right)$. While increasing the inflation pressure of the rear tires to increase the cornering stiffness coefficient by $25 \%$ will increase the vehicle under-steer 
behavior $\left(\mathrm{K}_{\mathrm{us}}=+0.0292 \mathrm{rad}\right)$ compared with the nominal value $\left(\mathrm{K}_{\mathrm{us}}=+0.0001 \mathrm{rad}\right)$. This underlines the importance of the tire inflation pressure on the vehicle response and stability.

The simulation results showed that for the slight under-steer behavior of the vehicle if a step input of side force is applied on its c.g its yaw velocity increases in the positive direction up to $8.8 \times 10^{-6} \mathrm{rad} / \mathrm{s}$ i.e. it turns away slightly from the side force. By decreasing the cornering stiffness of the rear tires with $25 \%$ the vehicle behavior will change from under-steer to oversteer that if a step input of side force is applied on its c.g its yaw velocity increases in the negative direction i.e. it turns toward the side force. By increasing the cornering stiffness of the rear tires with $25 \%$ the vehicle under-steer behavior increases that if a step input of side force is applied on its c.g its yaw velocity increases in the positive direction i.e. it turns away from the side force and these results completely agrees with well-established finding of Wong, [14].

\section{References}

[1] Heshmat, M.T., Abdel-Aziz, M., Rabie M. Galal, Dwidar M. Sabry, "Dynamic Performance of a Three-Wheeled Vehicle Steering System: Part 1: Steering System Incorporating Directional Control Valve", Proceedings of the 15th international conference on aerospace sciences \& aviation technology, May 28-30, 2013.

[2] Klyde, D.H., Magdaleno, R.E., Myers, T.T., and Reinsberg, J., "Development and Evaluation of Aircraft Ground Handling Maneuvers and Metrics," AIAA Paper No. 2001-4011 presented at the Atmospheric Flight Mechanics Conference, Montreal, Canada, Aug. 2001.

[3] Klyde, D.H., Magdaleno, R.E., and Reinsberg, J.G., "The Effect of Tire Pressure on Vehicle Ground Handling." AIAA Paper No. 2002-4798 presented at the Atmospheric Flight Mechanics Conference, Monterey, CA. 2002.

[4] Klyde, D.H., Myers, T.T., Magdaleno, R.E., and Reinsberg, J.G., "Identification of the Dominant Ground Handling Characteristics of a Navy Jet Trainer," J. of Guidance, Control, and Dynamics, Vol. 25, No. 3, May-June 2002.

[5] Tayea, M.S., Emam, M.A., Shaaban, S.M., El-Demerdash, S.M., and Rabie, M.G., "Dynamic Performance of Electro-hydraulic Steering System for Off-road Vehicles", Int. J. of Vehicle Structures \& Systems, Chennai, India, Volume 4, Issue 1, 2012, ISSN: 0975-3060 pp 1-9.

[6] Ibrahim, S.Y., Rabie, M.G., and Lotfy, A.H., "Experimental and Theoretical Investigation of the Performance of the Servo-actuator of a Hydraulic Power Steering System", Proceedings of the 8th AMME Conf., M.T.C., Cairo, May 1998, pp 395-407.

[7] Joseph, D., "Automakers prepare for by-wire revolution", Design News, pp. S9-S16, 2001.

[8] Haggag, S. "Development of fault-tolerant steer-by-wire system for earth moving equipment". PhD dissertation, university of Illinois at Chicago, Chicago, IL, 2002.

[9] Rabie, M.G., "Fluid Power Engineering", McGraw-Hill Professional, NY, USA, 2009.

[10] Rabie, M.G., “Automatic Control for Mechanical Engineers”, ISBN 977-17-9869-3, 2010.

[11] Starr, P.J., Solar Vehicle Design Seminar Handout, "Summary of Current Concepts and Major Tasks", Report for ME 5190, 1991.

[12] Schulz, B.D., "Development of a Computer-Aided Design Tool for the Initial Layout of a Solar Powered Vehicle", Report for ME 5742, 1994.

[13] Patrick, J. Starr, "Designing Stable Three Wheeled Vehicles, With Application to Solar Powered Racing Cars", Mechanical Engineering Department University of Minnesota.

[14] Wong, J.Y., "Theory of ground vehicles", 3rd ed., john Wiley\& Sons Inc., Ottawa, Canada, 2001. 
[15] Rankin, J., "Bifurcation Analysis of Nonlinear Ground Handling of Aircraft", University of Bristol, United Kingdom, 2010.

[16] Phillips, W. F., "Mechanics of flight", Wiley, 2004.

[17] Frederico, R. G., Eugene A. M., "A Collection of Nonlinear Aircraft Simulations in MATLAB" Langley Research Center, Hampton, Virginia, National Aeronautics and Space Administration Langley Research Center Hampton, Virginia 23681-2199 NASA/TM-2003-212145, 2003.

[18] Sonnevenldt, L., "Nonlinear F-16 Model Description", Faculty Of Aerospace Engineering, Delft University of Technology, The Netherlands, 2006.

[19] Gillespie, T.D., "Fundamentals of vehicle dynamics", SAE Inc., 1992. 